\title{
Body-Worn Antennas for Body-Centric Wireless Communications
}

Kammersgaard, Nikolaj Peter Iversen; Kvist, Søren H.; Ôzden, Sinasi ; Thaysen, Jesper; Jakobsen, Kaj Bjarne

\section{Published in:}

Proceedings of 2014 Loughborough Antennas and Propagation Conference

Link to article, DOI:

10.1109/lapc.2014.6996307

Publication date:

2014

Link back to DTU Orbit

Citation (APA):

Kammersgaard, N. P. I., Kvist, S. H., Ôzden, S. ., Thaysen, J., \& Jakobsen, K. B. (2014). Body-Worn Antennas for Body-Centric Wireless Communications. In Proceedings of 2014 Loughborough Antennas and Propagation Conference IEEE. https://doi.org/10.1109/lapc.2014.6996307

\section{General rights}

Copyright and moral rights for the publications made accessible in the public portal are retained by the authors and/or other copyright owners and it is a condition of accessing publications that users recognise and abide by the legal requirements associated with these rights.

- Users may download and print one copy of any publication from the public portal for the purpose of private study or research.

- You may not further distribute the material or use it for any profit-making activity or commercial gain

- You may freely distribute the URL identifying the publication in the public portal 


\title{
Body-Worn Antennas for Body-Centric Wireless Communications
}

\author{
(Invited Paper) \\ Nikolaj P. I. Kammersgaard*†, Søren H. Kvist ${ }^{\dagger}$, Sinasi Özden ${ }^{\dagger}$, Jesper Thaysen ${ }^{\dagger}$, and Kaj B. Jakobsen* \\ ${ }^{*}$ Department of Electrical Engineering, Electromagnetic Systems, Technical University of Denmark, \\ Ørsteds Plads, Building 348, DK-2800 Kgs. Lyngby, Denmark \\ ${ }^{*}$ kbjelelektro.dtu.dk, ${ }^{* \dagger}$ s110371@student.dtu.dk \\ ${ }^{\dagger}$ GN ReSound A/S, Lautrupbjerg 7, DK-2750 Ballerup, Denmark \\ †skviste, jthaysene, siozden@gnresound.com
}

\begin{abstract}
Ear-to-ear (E2E) on-body propagation and on-body antennas for body-centric wireless communications are presented.
\end{abstract}

\section{INTRODUCTION}

Body-centric wireless communications have received much attention in the literature in recent years. This is due to the rise of small body-worn devices, which need to communicate wirelessly in order to offer improved functionality to the user. The Industrial, Scientific and Medical (ISM) band at $2.4 \mathrm{GHz}$ is license free worldwide, and is therefore used to enable many Wireless Body Area Network (WBAN) applications. Additionally, all modern mobile phones are already equipped to communicate at $2.4 \mathrm{GHz}$ by the use of the widespread Bluetooth $^{\circledR}$ protocol.

Hearing Instruments (HIs) are a good example of such small body-worn devices, that have become increasingly advanced in recent years. Modern top-line HIs are thus expected to be able to communicate wirelessly with mobile accessories, such as audio streamers and mobile phones. Furthermore, the binaurally fitted HIs are needed to communicate wirelessly with each other, ear-to-ear, in order to synchronize the amplification settings between the HIs. Further, it is possible to obtain audiological advantages, which, e.g. eases conversation in noisy areas. In order to conserve power, the accessorylink and the ear-to-ear link need to utilize the same radio and antenna. The challenge in using $2.4 \mathrm{GHz}$ is that the head is lossy at these frequencies, with a skin depth $\delta_{\mathrm{s}} \approx 21 \mathrm{~mm}$ [1], [2]. Therefore, the energy cannot propagate through the head. Instead the energy propagates around the head as creeping waves [2], [3].

The HIs can be classified in four main types, see Fig. 1. The Behind-The-Ear (BTE) and the Receiver-In-the-Ear (RIE) HIs sit behind the ear, as shown in Fig. 1a and Fig. 1b, respectively. The In-The-Ear (ITE) and In-The-Canal (ITC) types are custom-made to fit the individual ear canals, and are shown in Fig. 1c and Fig. 1d, respectively. Common to all four types is that they are generally made as small as possible, in an effort to conceal the devices.

The early work on body-worn antennas and propagation

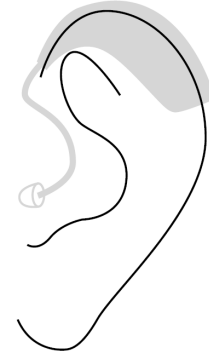

(a)

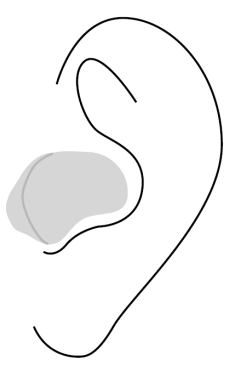

(c)

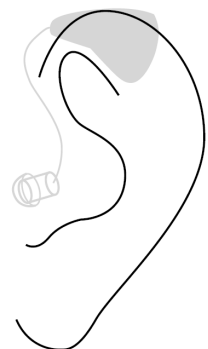

(b)

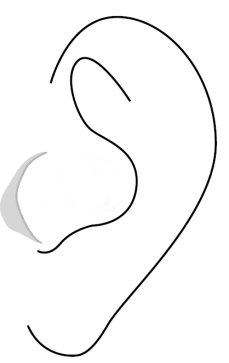

(d)
Fig. 1. The hearing instrument (HI) types in the use position for Behindthe-Ear (BTE) (a), Receiver-in-the-Ear (RIE) (b), In-the-Ear (ITE) (c), and the smaller versions of the ITE, the In-the-Canal (ITC) and Completely-inthe-Canal (CIC) (d) [2].

mainly involved off-body antennas and propagation, for use with devices such as mobile phones. These handsets and their antennas were rather large, since size was dictated by other components than the antenna. By comparison, todays body-worn devices are vanishingly small; A development that is driven by the availability of ever smaller electronic components. Thus, due to their small size compared to the wavelength at $2.4 \mathrm{GHz}$, the HIs can be be viewed almost as point sources, which can be leveraged as a vehicle to explore the on-body propagation.

In this presentation, the characteristics of the ear-to-ear on-body propagation will be reviewed. Additionally, some of the many examples of body-worn antennas found in the literature will be reviewed, e.g., [4]-[23], including some that 


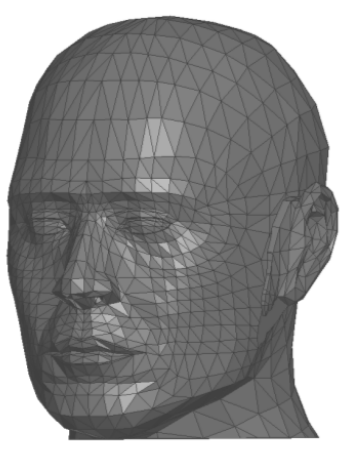

(a)

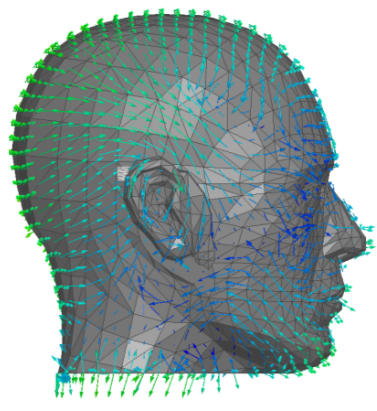

(c)

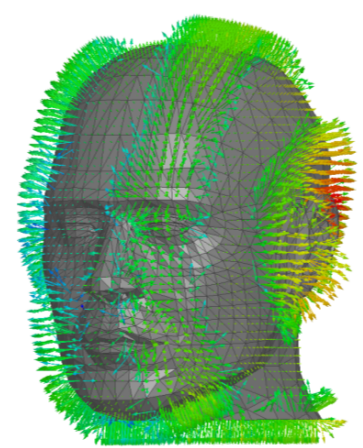

(b)

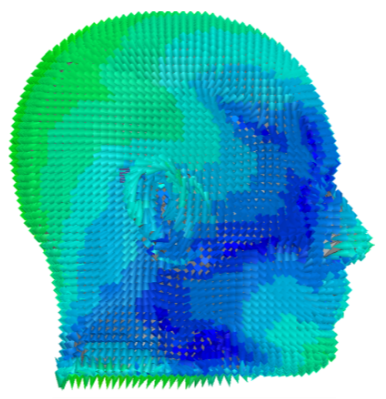

(d)
Fig. 2. The SAM head with ears (a) and electric field vectors (b) and Poynting vector showing the direction (c) and the interference pattern (d) [24], [25], [26].

are suitable for use in small body-worn devices, such as HIs.

\section{EAR-To-Ear On-Body Propagation}

The $2.4 \mathrm{GHz}$ ear-to-ear propagation effects have been investigated in [25], [26], where the ear-to-ear on-body path gain was measured on the Specific Anthropomorphic Mannequin (SAM) head model. It was shown that the electromagnetic waves creep around the head along different paths, and combine in an interference pattern that determines the ear-to-ear path gain. To illustrate the creeping waves, a realistic SAM head with ears was used and a small antenna was placed behind each ear [24]. The SAM head and the simulated electric field that is radiated from the antenna are shown in Fig. $2 \mathrm{a}$ and $2 \mathrm{~b}$, respectively. The electric field vectors are seen to be normal to the surface of the head and the creeping waves are seen to propagate along the surface of the head. Two plots of the Poynting vector a few millimeters above the head is shown for two vector arrow sizes to illustrate the orientation along the head surface and the interference pattern, see Fig. 2c and Fig. $2 \mathrm{~d}$, respectively. Thus, the on-body propagation can propagate along multiple paths around the human body, to combine in a pattern of constructive or destructive interference, which in general will depend on the shape of the body, the position of the antenna, and the on-body radiation pattern of the antenna.

To find the attenuation experienced by the wave as it creeps around the head, it is modelled as a series of elliptical cylinders. The attenuation for one path is [27], [28]

$$
W=\mathrm{e}^{-L}
$$

where $L$ is the complex attenuation in neper on an elliptical PEC cylinder given by [29]

$$
\begin{aligned}
& L=\sqrt[3]{\frac{k_{0}}{2}\left(\frac{3 \pi a b}{8}\right)^{2}} \mathrm{e}^{\frac{j \pi}{6}} \\
& \cdot \int_{\varphi_{1}}^{\varphi_{2}} \frac{a b}{\left(a^{4} \cos ^{2} \varphi+b^{4} \sin ^{2} \varphi\right)\left(a^{2} \cos ^{2} \varphi+b^{2} \sin ^{2} \varphi\right)} \mathrm{d} \varphi
\end{aligned}
$$

where $a$ is the major axis and $b$ is the minor axis of the elliptical cylinder, $\varphi_{1}$ and $\varphi_{2}$ are the angles on the elliptical cylinder and the angle that the waves creeps on the cylinder is $\varphi_{2}-\varphi_{1}$ thus the path length $d$ that the wave travels along the surface of the elliptical cylinder head is [29], [30]

$$
d=a b \int_{\varphi_{1}}^{\varphi_{2}} \sqrt{\frac{a^{4} \cos ^{2} \varphi+b^{4} \sin ^{2} \varphi}{\left(a^{2} \cos ^{2} \varphi+b^{2} \sin ^{2} \varphi\right)^{3}}} \mathrm{~d} \varphi .
$$

The waves that creep around the head can then be modeled as a sum of $N$ waves that each travel along an elliptical path $n$ on the head of path length $d_{n}$. The ear-to-ear on-body path gain $\frac{P_{\mathrm{R}}}{P_{\mathrm{T}}}$ can then be expressed as [30]

$$
\frac{P_{\mathrm{R}}}{P_{\mathrm{T}}}=\frac{\lambda_{0}^{2}}{4 \pi^{2}}\left|\frac{2 \pi}{\alpha_{N}-\alpha_{1}} \sum_{n=1}^{N} \frac{\sqrt{G_{\mathrm{T}, n} G_{\mathrm{R}, n}} \mathrm{e}^{-L_{n}} \mathrm{e}^{-j k_{0} d_{n}}}{d_{n}} \Delta \alpha\right|^{2},
$$

where $\lambda_{0}$ and $k_{0}$ are the wavelength and wave number in free space, respectively. Each of the creeping waves are weighted by the on-body gain that is associated with the $n^{\text {th }}$ path for the transmitter and the receiver antenna, $G_{\mathrm{T}, \mathrm{n}}$ and $G_{\mathrm{R}, \mathrm{n}}$, respectively. The $N$ creeping wave contributions to the received signal are then weighted by $\Delta \alpha$ and added, which is essentially a numerical integration over the angle $\alpha$. In [30] it is shown that an accurate model can be obtained for $N=50$ paths.

\section{ON-BODY ANTENNAS}

Body-worn antennas can be classified into on-body and offbody antennas. To obtain a high on-body path gain $\left(\left|S_{21}\right|\right)$ the on-body antenna is to radiate such that the electric field is perpendicular to the surface of the body, see Fig. 3b. This will ensure an efficient launch of a creeping wave [3], [31] [33]. Further, the antenna should radiate along the surface of the body. Many on-body antennas have been presented in the literature, e.g., [4]-[9], [15], [24], [34]-[36]. However, to be useful, e.g., in HIs, the antenna must be physically small in order to fit the devices-but not necessarily electrically small at $2.4 \mathrm{GHz}$.

The on-body antennas can be realized as either unbalanced or balanced antennas. Five examples are shown in Fig. 4 and 5, respectively. In Fig. $4 \mathrm{a}$ and $4 \mathrm{~b}$ are shown two unbalanced antennas, a straight monopole antenna that rests on top of 
(a)

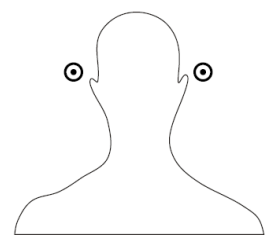

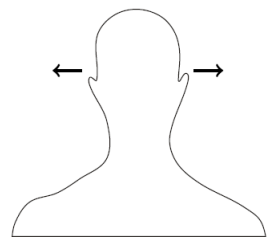

(b)
Fig. 3. Hearing-instrument antenna configurations. HI antennas oriented parallel (a) and perpendicular (b) to the head [37]

the ear and a meandered monopole antenna that is fed at the center of the side of the ground plane. Two examples of balanced antennas are shown in Fig. $4 \mathrm{c}$ and $4 \mathrm{~d}$, respectively; one antenna with two parallel, circular plates, see Fig. 4c; and one with two parallel rings, see Fig. 4d. A magnetic dual, a meandered slot loop is shown in Fig. 5. In Fig. 6 is shown the current distribution on the unbalanced monopole shown in Fig. 4a. It is seen that the current runs tangentially to the head, high and low current density is shown in red and blue, respectively. In Fig. 7 is shown a prototype of the on-body antenna in Fig. 4c fitted with a balun.

It was shown in [30] that an on-body radiation pattern that optimizes the ear-to-ear on-body path gain can be synthesized. The radiation pattern synthesis is shown in Fig. 8. The onbody radiation pattern was synthesized as a weighted sum of the first six spherical wave mode expansion coefficients, $Q_{j}$, in order to emulate an electrically small antenna. The mode weights were found by the use of a genetic algorithm in combination with the ear-to-ear path gain model described above. The optimization was converged after 100 iterations of the genetic algorithm, see Fig. 8a. The weights of the spherical wave expansion coefficients, $Q_{j}$, are shown in Fig. 8b. The synthesized on-body radiation pattern is shown in Fig. 8c, with the orientation of the SAM head indicated by the dotted line.

\section{CONCLUSION}

Ear-to-ear on-body propagation has been reviewed with illustrations of creeping waves on a realistic specific anthropomorphic mannequin (SAM) head with ears. A theoretical model for the E2E on-body path gain was presented. Different types of on-body antennas have been presented along with an on-body radiation pattern that is synthesized by the use of spherical wave expansion in order to optimize the E2E onbody path gain.

\section{REFERENCES}

[1] P. S. Hall and Y. Hao, Antennas and propagation for body-centric wireless communications. Artech House, Inc. Norwood, MA, USA, 2006.

[2] S. H. Kvist, Antennas and Propagation for Body-Centric Wireless Communications. Ph.D. dissertation, DTU Elektro, Technical University of Denmark (DTU), Kgs. Lyngby, Denmark, ISBN 978-87-92465-47-4, 2013.

[3] P. S. Hall, Y. Nechayev, and L. Akhoondzadeh-Asl, "Surface and creeping waves excitation by body-worn antennas," 2010 Loughborough Antennas and Propagation Conference, LAPC 2010, pp. 48-51, 2010.

[4] G. A. Conway and W. G. Scanlon, "Antennas for over-body-surface communication at $2.45 \mathrm{GHz}$," IEEE Transactions on Antennas and Propagation, vol. 57, no. 4, pp. 844-855, 2009.

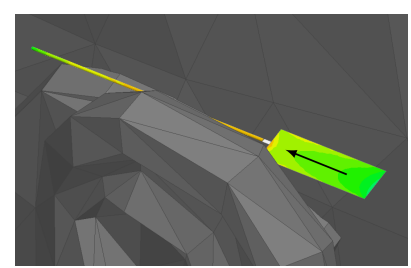

(a)

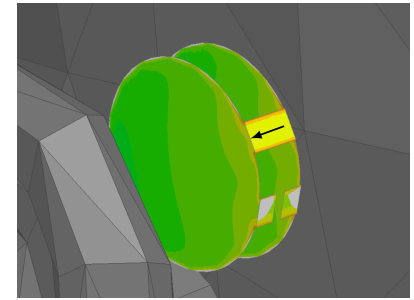

(c)

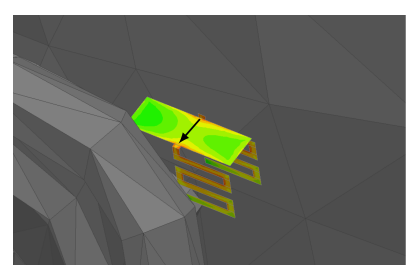

(b)

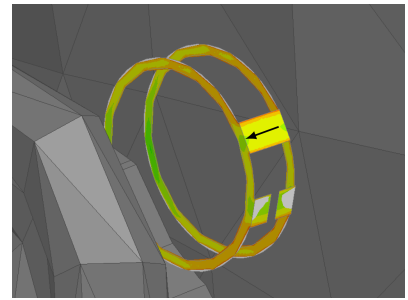

(d)
Fig. 4. On-body antenna types shown with simulated surface current distributions. Two types of unbalanced antennas, a straight monopole antenna that rests on top of the ear (a) and a meandered monopole antenna that is fed at the center of the side of the ground plane (b). Two types of balanced antennas, one antenna with two parallel, circular plates (c) and one with two parallel rings (d) [2], [35].

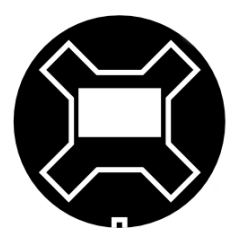

Fig. 5. Meandered slot loop on-body antenna type. The rectangular battery compartment is shown in white in the center [36].

[5] G. A. Conway, S. L. Cotton, and W. G. Scanlon, "An antennas and propagation approach to improving physical layer performance in wireless body area networks," IEEE Journal on Selected Areas in Communications, vol. 27, no. 1, pp. 27-36, 2009.

[6] N. Chahat, M. Zhadobov, L. Le Coq, and R. Sauleau, "Wearable endfire textile antenna for on-body communications at $60 \mathrm{GHz}$," IEEE Antennas and Wireless Propagation Letters, vol. 11, pp. 799-802, 2012.

[7] Q. Bai and R. Langley, "Crumpling of PIFA textile antenna," IEEE Transactions on Antennas and Propagation, vol. 60, no. 1, pp. 63-70, 2012.

[8] T. Alves, R. Augustine, P. Queffelec, M. Grzeskowiak, B. Poussot, and J. M. Laheurte, "Polymeric ferrite-loaded antennas for on-body

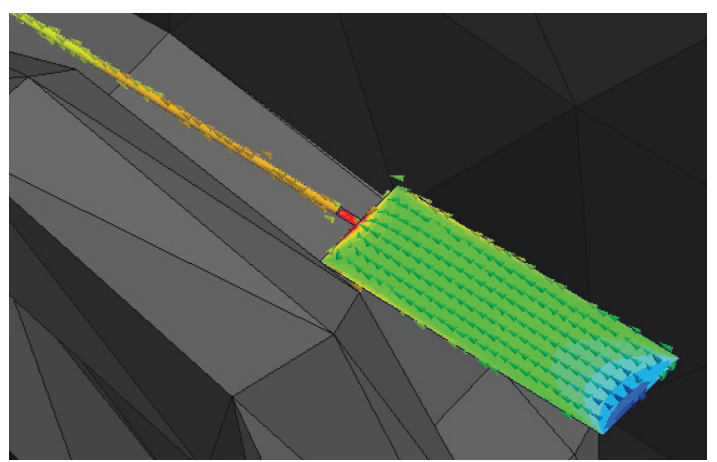

Fig. 6. Current distribution on the body-worn antenna shown in Fig. 4a [38] 


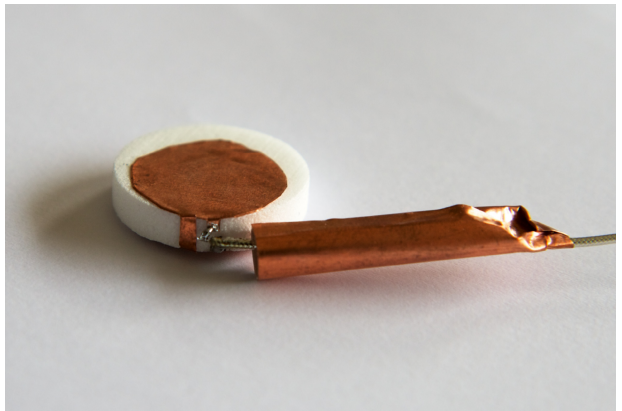

Fig. 7. Prototype of the on-body antenna shown in Fig. 4c [34].

communications," Microwave and Optical Technology Letters, vol. 51, no. 11, pp. 2530-2533, 2009.

[9] L. Akhoondzadeh-Asl, Y. Nechayev, P. S. Hall, and C. C. Constantinou, "Parasitic array antenna with enhanced surface wave launching for onbody communications," IEEE Transactions on Antennas and Propagation, vol. 61, no. 4, pp. 1976-1985, 2013.

[10] C.-H. Lin, K. Saito, M. Takahashi, and K. Ito, "A compact planar inverted-F antenna for $2.45 \mathrm{GHz}$ on-body communications," IEEE Transactions on Antennas and Propagation, vol. 60, no. 9, pp. 4422 4426, 2012.

[11] A. M. Faiz, T. Alves, B. Poussot, and J. M. Laheurte, "Diversity antenna combining slot-loop DRA for BAN applications," Electronics Letters, vol. 48, no. 1, pp. 7-8, 2012.

[12] B. Sanz-Izquierdo, J. A. Miller, J. C. Batchelor, and M. I. Sobhy, "Dualband wearable metallic button antennas and transmission in body area networks," IET Microwaves Antennas and Propagation, vol. 4, no. 2, pp. 182-190, 2010.

[13] S. Rao, N. Llombart, E. Moradi, K. Koski, T. Bjorninen, L. Sydanheimo, J. M. Rabaey, J. M. Carmena, Y. Rahmat-Samii, and L. Ukkonen, "Antenna applications corner: miniature implantable and wearable onbody antennas: Towards the new era of wireless body-centric systems," IEEE Antennas and Propagation Magazine, vol. 56, no. 1, pp. 271-291, 2014.

[14] G. Fontgalland, U. Olgun, and J. L. Volakis, "Low-profile vertically polarized printed antenna for body-worn applications," 2013 IEEE Antennas and Propagation Society International Symposium (APSURSI), pp. 986-986, 2013.

[15] A. K. Skrivervik, D. D. Cara, J. Trajkovikj, and J.-F. Zurcher, "Compact UWB antennas for wireless body area networks (W-BANs)," 2014 IEEEAPS Topical Conference on Antennas and Propagation in Wireless Communications (APWC), pp. 125-128, 2014

[16] J. Bringuier, R. Mittra, and K. Yoo, "Modeling and design of wideband antennas for body area networks (BANs)," IEEE Region 10 Annual International Conference, Proceedings/TENCON, 2007.

[17] W. G. Whittow, C. C. Njoku, and Y. C. Vardaxoglou, "Fine scale simulations of patch antennas with heterogeneous substrates," 2013 USNC-URSI Radio Science Meeting (Joint with AP-S Symposium), p. 223, 2013.

[18] A. Bisognin, J. Thielleux, W. Wei, D. Titz, F. Ferrero, P. Brachat, G. Jacquemod, H. Happy, and C. Luxey, "Inkjet coplanar square monopole on flexible substrate for $60 \mathrm{GHz}$ applications," IEEE Antennas and Wireless Propagation Letters, vol. 13, pp. 435-438, 2014.

[19] L. K. Larsen, S. H. Kvist, W. H. Yatman, J. Thaysen, and K. B. Jakobsen, "Mini-remote-control antenna for on-body wireless communication systems," 2012 Loughborough Antennas and Propagation Conference, 2012.

[20] A. Ruaro, J. Thaysen, S. Gülstorff, K. B. Jakobsen, and S. H. Kvist, "Influence of the antenna impedance variation and input matching network Q on LNA key figures," LAPC 2012 - 2012 Loughborough Antennas and Propagation Conference, 2012.

[21] S. Pehrson, S. H. Kvist, K. B. Jakobsen, and J. Thaysen, "Morphological investigation of the differences on the ear-to-ear path gain and the packet loss at $2.45 \mathrm{GHz}$," 34th Annual Antenna Measurement Techniques Association Symposium 2012, pp. 43-48, 2012.

[22] P. F. Medina, S. H. Kvist, K. B. Jakobsen, and J. Thaysen, "Transmit and receive diversity in body-centric wireless communications," 34th Annual

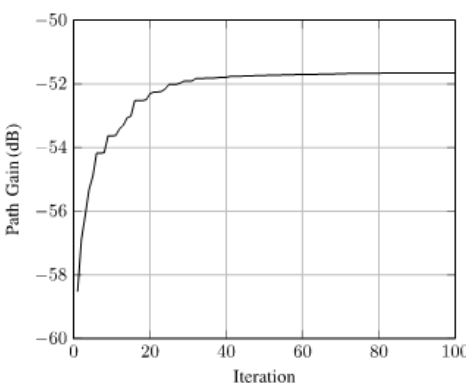

(a)

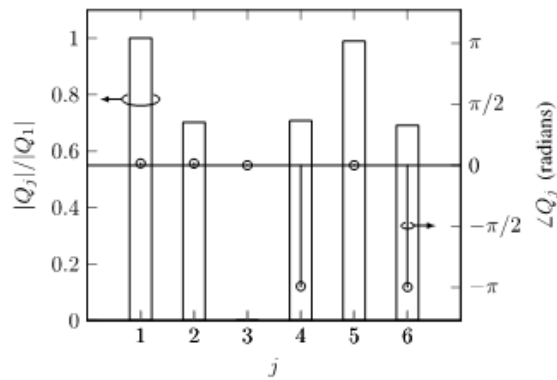

(b)

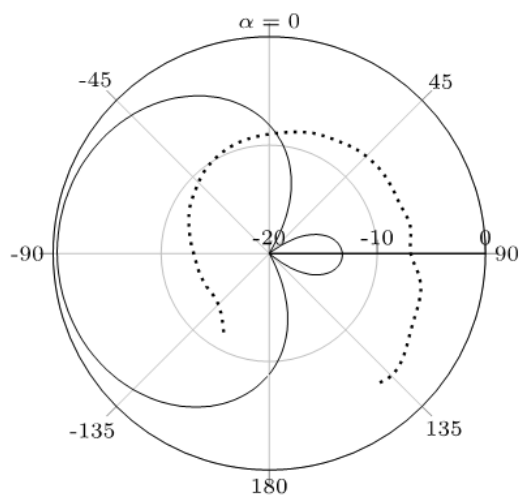

(c)

Fig. 8. Path gain convergence of the genetic algorithm with a genome of the first 6 spherical wave mode weights (a) and the spherical wave expansion coefficients, $Q_{j}$, after 100 iterations of the genetic algorithm (b). Synthesized on-body radiation pattern such that the ear-to-ear on-body path gain is optimized. The orientation of the SAM head is indicated by the dotted line (c) [2].

Antenna Measurement Techniques Association Symposium 2012, pp. 38 42, 2012.

[23] S. H. Kvist and K. B. Jakobsen, "Investigation of the chest-ear radio propagation channel," EuCAP 2010 - the 4th European Conference on Antennas and Propagation, p. 5505460, 2010.

[24] S. H. Kvist, S. Özden, J. Thaysen, and K. B. Jakobsen, "Improvement of the ear-to-ear path gain at $2.45 \mathrm{GHz}$ using parasitic antenna element," 2012 6th European Conference on Antennas and Propagation, pp. 944 947, 2012.

[25] S. H. Kvist, J. Thaysen, and K. B. Jakobsen, "Investigation of the earto-ear radio propagation channel," in European Conference on Antennas and Propagation, 2011, pp. 3796-3800.

[26] S. Kvist, J. Thaysen, and K. B. Jakobsen, "The effect of the head size on the ear-to-ear radio-propagation channel for body-centric wireless 
networks," in Loughborough Antennas \& Propagation Conference, 2010 pp. $345-348$.

[27] R. Chandra and A. J. Johansson, "An elliptical analytic link loss mode for wireless propagation around the human torso," Proceedings of 6th European Conference on Antennas and Propagation, EuCAP 2012, pp. 3121-3124, 2012.

[28] — , "A link loss model for the on-body propagation channel for binaural hearing aids," IEEE Transactions on Antennas and Propagation, vol. 61, no. 12, pp. 6180-6190, 2013.

[29] C. A. Balanis and J. Peters, L., "Aperture radiation from an axially slotted elliptical conducting cylinder using geometrical theory of diffraction," IEEE Transactions on Antennas and Propagation, vol. AP-17, no. 4, pp. 507-513, 1969.

[30] S. H. Kvist, J. Thaysen, and K. B. Jakobsen, "Ear-to-ear on-body channel model for hearing aid applications," IEEE Transactions on Antennas and Propagation, accepted 2014.

[31] P. Hall, Y. Hao, Y. Nechayev, A. Alomainy, C. Constantinou, C. Parini, M. Kamarudin, T. Salim, D. Hee, R. Dubrovka, A. Owadally, W. Song, A. Serra, P. Nepa, M. Gallo, and M. Bozzetti, "Antennas and propagation for on-body communication systems," IEEE Antennas and Propagation Magazine, vol. 49, no. 3, pp. 41-58, 2007.

[32] L. Akhoondzadeh-Asl, P. S. Hall, and Y. Nechayev, "Wave excitation on human body by a short dipole," EuCAP 2010 - the 4th European Conference on Antennas and Propagation, 2010.
[33] P. S. Hall, Y. I. Nechayev, and M. R. Kamarudin, "Antennas for on-body communication systems," Proceedings - 2005 IEEE International Workshop on Antenna Technology: Small Antennas and Novel Metamaterials, IWAT 2005, vol. 2005, pp. 17-20, 2005.

[34] S. H. Kvist, K. B. Jakobsen, and J. Thaysen, "Design and measurement of a $2.45 \mathrm{GHz}$ on-body antenna optimized for hearing instrument applications," 34th Annual Antenna Measurement Techniques Association Symposium 2012, pp. 33-37, 2012.

[35] N. P. I. Kammersgaard, S. H. Kvist, J. Thaysen, and K. B. Jakobsen, "Inthe-ear spiral monopole antenna for hearing instruments," Electronics Letters, vol. 50, no. 21, 2014 (accepted)

[36] W. H. Yatman, L. K. Larsen, S. H. Kvist, J. Thaysen, and K. B. Jakobsen, "In-the-ear hearing-instrument antenna for ISM-band body-centric earto-ear communications," LAPC 2012 - 2012 Loughborough Antennas and Propagation Conference, pp. 1-4, 2012.

[37] S. H. Kvist, J. Thaysen, and K. B. Jakobsen, "Time-domain measurement of the ear-to-ear on-body path gain at $2.45 \mathrm{GHz}$ in a radio anechoic environment," Loughborough Antennas \& Propagation Conference (LAPC), 2012.

[38] —, "Polarization of unbalanced antennas for ear-to-ear on-body communications at $2.45 \mathrm{GHz}$,' Loughborough Antennas \& Propagation Conference, pp. 1-4, 2011. 